\title{
Dietary Habits of Students Enrolled in Faculties of Health Sciences: A Cross-sectional Study
}

Sarah AlJohani ${ }^{1}$, Mahmoud Salam ${ }^{2}$, Ala'a BaniMustafa ${ }^{3}$, Abdul Rehman Z. Zaidi 4, 5, 6 , Abdulaziz A. Aljohani $^{7}$, Adel Almutairi ${ }^{1}$, Majed A. Aljohani ${ }^{7}$, Mohammed AlSheef ${ }^{8}$

1. Miscellaneous, King Saud bin Abdulaziz University for Health Sciences, Riyadh, SAU 2. Nursing, Hariri School of Nursing, American University of Beirut, Beirut, LBN 3. King Abdullah International Medical Research Center (KAIMRC), King Saud bin Abdulaziz University for Health Sciences, Riyadh, SAU 4. Internal Medicine, King Fahad Medical City, Riyadh, SAU 5. Medicine, Alfaisal University, Riyadh, SAU 6. Research, California Institute of Behavioral Neurosciences and Psychology, Fairfield, USA 7. Medicine, King Saud University, Riyadh, SAU 8. Medicine, King Fahad Medical City, Riyadh, SAU

Corresponding author: Mahmoud Salam, mahmoudsalam@hotmail.com

\section{Abstract}

\section{Introduction}

It is often presumed that students of health sciences are more vigilant about their diet. This study assessed the prevalence of unhealthy dietary habits and identified its associated factors among students enrolled at a large university for health sciences in the Middle East.

\section{Methods}

A cross-sectional study, using a set of pre-validated and anonymous dietary tools, was conducted in 2018. The self-reported students' characteristics and prevalence of 10 unhealthy dietary habits were collected.

\section{Results}

Males were significantly more likely have irregular meal times $(\beta=0.425$, adjusted [adj.] odds ratio [OR] = 1.5 ) and insufficient seafood consumption $(\beta=0.55$, adj. $O R=1.7)$ compared to females, adj. $P=0.046$ and adj. $P=0.012$, respectively. Students in their third year and above $(\beta=0.857$, adj. OR $=2.2)$ reported more insufficient water intake compared to students in the first and second years, adjusted $P=0.003$. Obesity in students was a significant associated factor with fast food consumption $(\beta=0.48$, adj. $\mathrm{OR}=1.8$ ), nighteating habits ( $\beta=0.27$, adj. $\mathrm{OR}=1.3$ ) and skipping meals $(\beta=0.41$, adj. $\mathrm{OR}=1.5$ ) compared to normal weight students, adjusted $P=0.002$, adj. $P=0.004$, and adj. $P=0.003$, respectively.

\section{Conclusions}

Compliance with healthy dietary habits among students was less than optimal. Special consideration should be paid to gender and obesity that have been associated with insufficient water intake, irregular meal times,

Received 10/15/2019

Review began 10/21/2019 Review ended 10/23/2019 Published 10/28/2019

\section{(c) Copyright 2019}

AlJohani et al. This is an open access article distributed under the terms of the Creative Commons Attribution License CC-BY 3.0., which permits unrestricted use, distribution, and reproduction in any medium, provided the original author and source are credited.
Categories: Medical Education, Preventive Medicine, Public Health

Keywords: medical education, healthy, diet, unhealthy, health sciences, students, dietary habits, lifestyle, health care professionals

\section{Introduction}

Assessing whether a dietary habit is healthy or not and generating plans for weight control and disease prevention have been extensively presented in the literature. Various dietary assessment tools have been constructed and validated on various age groups and age/diseases specific populations. For instance, the Nutrition Literacy Assessment Instrument (NLit) demonstrated substantial factor validity and test-retest reliability in adult primary care patients, whereas a brief folate-specific food frequency questionnaire for Central and Eastern European population was considered as a valid tool for the assessment of folate intake in young women [1-2].

A self-reported dietary profile of any individual ought to be analyzed and evaluated at its specific components. For instance, a comprehensive dietary profile assessment should include questioning the individual on the intake of sugary drinks, sweetened foods, fruits/vegetables, and so on. A scoring system that scores, quantifies, and accumulates various scores of dietary habits into one summated score and sets a certain cut-off point might defer the attention of nutritionists from specific problematic dietary habits. These tools might not be fully comprehensive to question subjects about other dietary patterns such as the regularity of meal times, skipping meals, or even dehydration. Therefore, analyzing each dietary habit and evaluating it against rigorous age/disease-specific nutritional guidelines remains the most accurate method to meticulously determine the prevalence of unhealthy dietary habits. 
A poor dietary habit might influence the academic performance of students, whereas a weak academic performance might stress students out, leading them to adopt unhealthy dietary behaviors, as a method to overcome their frustration. For instance, some students who are under academic stressors might tend to eat more or vice versa. Students enrolled in health-related faculties such as medicine, nursing, pharmacy, and others are expected to be extra vigilant about their dietary habits, compared to students of other faculties. The level of knowledge on ideal eating habits and disease prevention is expected to be higher among students of health faculties, so their compliance with a healthy diet is anticipated to be higher too. We investigated the dietary habits of students enrolled in the faculties of health sciences at a large university in Riyadh, Saudi Arabia.

\section{Materials And Methods}

This was a cross-sectional study conducted among students enrolled at King Saud bin Abdulaziz University for Health Sciences (KSAU-HS), Riyadh, Saudi Arabia. This study aimed to assess the prevalence of a number of unhealthy dietary habits of college students in a large Middle Eastern university for health sciences. Approval was obtained from the Institutional Review Board (RC18/146) at King Fahad Medical City and the Saudi Ministry of National Guard-Health Affairs (SMNG-HA). Inaugurated in 2005, under the directory of SMNG-HA, KSAU-HS is a large-scale university with its main campus located in Riyadh (capital of Saudi Arabia) and two additional campuses in Eastern and Western regions of the Kingdom. KSAU-HS joins seven colleges, Colleges of Medicine, Dentistry, Pharmacy, Public Health and Health Informatics, Applied Medical Sciences, Nursing, and Science \& Health Professions. The number of students enrolled per each academic year in both undergraduate and postgraduate studies exceeds 6,000.

By convenience, a pre-validated English language survey was distributed among students in the academic year 2017-2018. Written informed consent was sought with no student identifiers collected. A team of data collectors included a student from the college of pharmacy and a research coordinator. The data collection tool assessed the students' characteristics, which are gender, age (years), BMI $\left(\mathrm{kg} / \mathrm{m}^{2}\right)$ categorized into underweight, normal weight, pre-obese, and obese based on World Health Organization (WHO) and locally conducted study [3]. Students were reminded that their participation and self-reported answers will be confidential and only for research purposes. Respondents included students from Colleges of Medicine $(n=116,31.2 \%)$, Dentistry $(n=49,13.2 \%)$, Pharmacy $(n=47,12.6 \%)$, Applied Medical Sciences $(n=98$, $26.3 \%)$, Nursing, and Science \& Health Professions $(n=62,16.7 \%)$.

A total of 10 dietary habits were evaluated as healthy or unhealthy based on published literature. Students were asked to describe their routine and standard dietary habits in the past two weeks. Drinking at least one sugar-sweetened beverage (200-250 ml), such as canned juices and sodas, on a daily basis was accounted for as an unhealthy dietary habit [4]. Students who drank less than two liters of water daily (gender adjusted) were classified as having an unhealthy habit, too [5]. The same applied to students who did not consume 400 $\mathrm{g}$ of fruits/vegetables on a daily basis and those who consumed fast food meals at least once per week [6-7]. Students who have irregular timings of meals, skipping meals, and night-eating habits were classified as unhealthy dietary habits [8-10]. Consuming unhealthy snacks between meals on a daily basis and drinking at least one energy drink on a weekly basis were classified as unhealthy [11-12]. Eating at least one meal (227 g) of seafood on a weekly basis was accounted for as a healthy dietary habit [13].

The statistical software SPSS version 25.0 has been used for data analysis. Descriptive statistics of categorical variables such as student characteristics and dietary habits were presented in frequency (n) and percentage (\%), while continuous variables were presented in mean ( $\bar{x})$ and standard deviation ( $\left.{ }^{ \pm} \mathrm{SD}\right)$.

Analytical statistics included Pearson's Chi-square $\left(\chi^{2}\right)$ for categorical outcomes. Outliers were excluded, while missing outcome variables were replaced by the mean of sample outcomes. Each dietary habit was accounted for as an individual outcome in 10 binary logistic regression models to identify whether gender, academic year, or BMI were significantly associated factors. Statistical significance was set at $P<0.05$.

\section{Results}

\section{Sample and outcome characteristics}

The sample comprised 392/430 (91\%) students who agreed to participate and submitted a complete survey, with a male-to-female ratio (1:1.3) and a mean of age $21 \pm 2$ years. A very less number of students were married (8; $2 \%$ ), and only 68 (17.3\%) had chronic diseases such as asthma, diabetes type I and/or hypertension. Their average BMI was $23 \pm 5$, with 225 (57\%) classified under the normal weight category and $117(28.8 \%)$ as pre-obese/obese. Those in their first two academic years were $146(37 \%)$, while those in their third \& above academic years were 246 (63\%). Almost 117 (30\%) were in the college of medicine, 109 (28\%) in applied medical sciences, 67 (17\%) in dentistry, and 99 (25\%) in two other faculties. The majority of the sample were in pursuit of a bachelor's degree 380 (97\%; Table 1$)$. 


\section{Cureus}

\begin{tabular}{|c|c|}
\hline & n (\%) $392(100.0)$ \\
\hline \multicolumn{2}{|l|}{ Gender } \\
\hline Females & $224(57.1)$ \\
\hline Males & $168(42.9)$ \\
\hline \multicolumn{2}{|c|}{ Age category (years) } \\
\hline$(\bar{x} \pm S D)$ & $21 \pm 2.2$ \\
\hline \multicolumn{2}{|l|}{ BMI } \\
\hline Underweight & 50 (12.8) \\
\hline Normal weight & $225(57.4)$ \\
\hline Pre-obesity & 78 (19.9) \\
\hline Obesity & $39(9.9)$ \\
\hline$(\bar{x} \pm S D)$ & $23.4 \pm 5.4$ \\
\hline \multicolumn{2}{|l|}{ Chronic disease } \\
\hline Yes & 68 (17.3) \\
\hline No & 324 (82.7) \\
\hline \multicolumn{2}{|l|}{ Academic year } \\
\hline First \& second & 146 (37.2) \\
\hline Third \& above & $246(62.8)$ \\
\hline
\end{tabular}

\section{TABLE 1: Distribution of basic characteristics among students}

$\mathrm{n}$ : frequency, \%: percentage, $\bar{x}$ : mean, SD: standard deviation

The prevalence of 10 unhealthy dietary habits is presented in Figure 1.

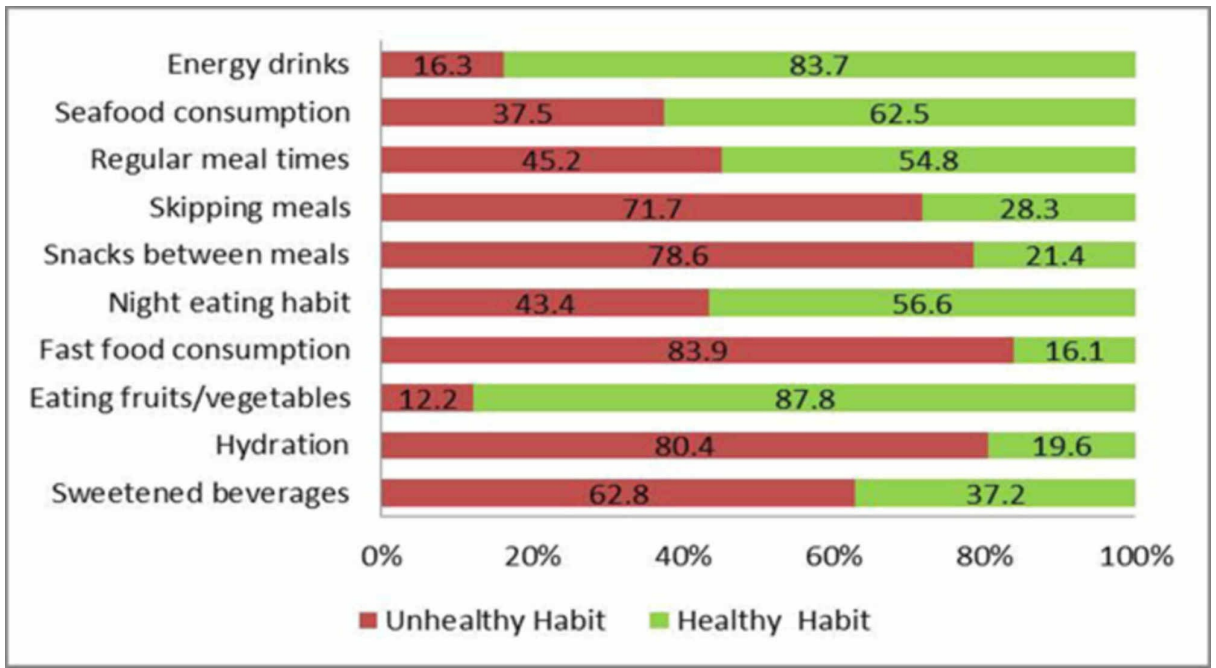

FIGURE 1: Distribution of unhealthy and healthy dietary habits among students

Unhealthy dietary habits found were drinking sugar-sweetened beverages (246; 62.8\%), insufficient daily amounts of water or hydration (315; 80.4\%), and consuming energy drinks (64; 16.3\%). Almost 177 (45\%) had irregular meal times, 308 (78.6\%) consumed unhealthy snacks between meals, and 281 (72\%) skipped 
meals, while 170 (43.4\%) had night-eating habits, all accounted as unhealthy dietary habits. Other unhealthy habits were prevalent in regard to insufficient eating of fruits/vegetables 48 (12.2\%), inadequate seafood consumption 147 (37.5\%), and fast food consumption 329 (83.9\%; as shown in Figure 1).

The prevalence of unhealthy dietary habits across sample characteristics is tabulated in Table 2 .

\begin{tabular}{|c|c|c|c|c|c|c|}
\hline & \multicolumn{2}{|l|}{ Gender } & \multicolumn{2}{|l|}{ Academic year } & \multicolumn{2}{|l|}{ BMI (category) } \\
\hline & Females & Males & First \& second & Third \& above & Underweight/ Normal & Pre-obese/ obese \\
\hline \multirow[t]{2}{*}{ Sweetened beverages } & $137(61.2)$ & 109(64.9) & $92(63.0)$ & 154(62.6) & $164(59.6)$ & $82(70.1)$ \\
\hline & \multicolumn{2}{|c|}{$X^{2}=0.568, P=0.451$} & \multicolumn{2}{|c|}{$x^{2}=0.007, P=0.935$} & \multicolumn{2}{|l|}{$X^{2}=3.834, P=0.050$} \\
\hline \multirow[t]{2}{*}{ Insufficient hydration } & 194(86.6) & $121(72.0)$ & $109(74.7)$ & 206(83.7) & 225(81.8) & $90(76.9)$ \\
\hline & \multicolumn{2}{|c|}{$\mathrm{X} 2=12.935, \mathrm{P}<0.01^{*}$} & \multicolumn{2}{|c|}{$X^{2}=4.788, P=0.029^{\star}$} & \multicolumn{2}{|l|}{$X^{2}=1.246, P=0.264$} \\
\hline \multirow[t]{2}{*}{ Drinking energy drinks } & $35(15.6)$ & 29(17.3) & $27(18.5)$ & $37(15.0)$ & $45(16.4)$ & 19(16.2) \\
\hline & \multicolumn{2}{|c|}{$X^{2}=0.188, P=0.664$} & \multicolumn{2}{|c|}{$\mathrm{X}^{2}=0.799, \mathrm{P}=0.371$} & \multicolumn{2}{|l|}{$X^{2}=0.001, P=0.976$} \\
\hline \multirow[t]{2}{*}{ Irregular meal times } & 114(50.9) & $101(60.1)$ & $81(55.5)$ & 134(54.5) & 158(57.5) & $57(48.7)$ \\
\hline & \multicolumn{2}{|c|}{$X^{2}=3.300, P=0.069$} & \multicolumn{2}{|c|}{$x^{2}=0.038, P=0.846$} & \multicolumn{2}{|l|}{$X^{2}=2.530, P=0.112$} \\
\hline \multirow{2}{*}{ Snacks between meals } & 183(81.7) & $125(74.4)$ & 122(83.6) & 186(75.6) & $217(78.9)$ & $91(77.8)$ \\
\hline & \multicolumn{2}{|c|}{$X^{2}=3.032, P=0.082$} & \multicolumn{2}{|c|}{$\mathrm{X}^{2}=3.441, \mathrm{P}=0.064$} & \multicolumn{2}{|l|}{$X^{2}=0.062, P=0.803$} \\
\hline \multirow[t]{2}{*}{ Skipping meals } & 174(77.7) & $107(63.7)$ & 111(76.0) & 170(69.1) & $187(68.0)$ & $94(80.3)$ \\
\hline & \multicolumn{2}{|c|}{$X^{2}=9.254, P=0.002^{*}$} & \multicolumn{2}{|c|}{$X^{2}=2.163, P=0.141$} & \multicolumn{2}{|l|}{$X^{2}=6.159, P=0.013^{*}$} \\
\hline \multirow[t]{2}{*}{ Night eating habit } & 91(40.6) & 79(47.0) & $66(45.2)$ & 104(42.3) & 106(38.5) & 64(54.7) \\
\hline & \multicolumn{2}{|c|}{$X^{2}=1.600, P=0.206$} & \multicolumn{2}{|c|}{$X^{2}=0.320, P=0.572$} & \multicolumn{2}{|l|}{$X^{2}=8.722, P=0.003^{\star}$} \\
\hline \multirow[t]{2}{*}{ Insufficient fruit/ vegetable } & 24(10.7) & 24(14.3) & $15(10.3)$ & $33(13.4)$ & $32(11.6)$ & 16(13.7) \\
\hline & \multicolumn{2}{|c|}{$x^{2}=1.140, P=0.286$} & \multicolumn{2}{|c|}{$X^{2}=0.841, P=0.359$} & \multicolumn{2}{|l|}{$X^{2}=0.318, P=0.573$} \\
\hline Insufficient seafood & $74(33.0)$ & 73(43.5) & $62(42.5)$ & 85(34.6) & 105(38.2) & 42(35.9) \\
\hline & $X^{2}=4.444$ & $P=0.035^{\star}$ & $x^{2}=2.448, P=$ & 0.118 & $X^{2}=0.183, P=0.669$ & \\
\hline Fast food consumption & 192(85.7) & 137(81.5) & $121(82.9)$ & 208(84.6) & 221(80.4) & 108(92.3) \\
\hline & $X^{2}=1.236$ & $P=0.266$ & $X^{2}=0.191, P=$ & 0.662 & $X^{2}=8.681, P=0.003^{\star}$ & \\
\hline
\end{tabular}

\section{TABLE 2: Unhealthy dietary habits across sample characteristics}

X2: Pearson's chi-square, t: Student's t-test; F: one-way ANOVA; P-value: statistically significant at $<0.05$, \%: percentage, ANOVA: analysis of variance; df: degree of freedom, $n$ : frequency, $x$ : mean, SD: standard deviation

A total of 194 females (86.6\%) and 206 (83.7\%) students in their third and above academic years reported insufficient water consumption compared to 121 (72.0\%) males and 109 (74.7\%) students in the first and second years, $P<0.01$ and $P=0.029$, respectively. A total of 174 (77.7\%) females and 94 (80.3\%) preobese/obese students tend to skip meals compared to 107 (63.7\%) males and 187 (68.0\%) normal-weight students, $P=0.002$ and $P=0.013$, respectively. A total of 64 (54.7\%) pre-obese/obese students also reported a higher prevalence of night-eating habits compared to 106 (38.5\%) normal weight students, $P=0.003$. Insufficient seafood consumption was higher among 73 (43.5\%) males compared to 74 (33.0\%) females, $P=$ 0.035, while fast food consumption was higher among 108 (92.3\%) obese students compared to 221 (80.4\%) normal-weight students, $P=0.003$ (Table 2).

After conducting logistic regression analyses (Table 3), female gender was a significant factor associated with insufficient water intake ( $\beta=-1.02$, adjusted [adj.] odds ratio $[\mathrm{OR}]=0.3)$ and skipping meals $(\beta=-0.75$, adj.OR $=0.5$ ) more than male gender, adj.P $<0.001$ and adj.P $=0.001$, respectively. On the other hand, male students were significantly more likely to report irregular meal times $(\beta=0.425$, adj.OR $=1.5$ ) and insufficient seafood consumption ( $\beta=0.55$, adj.OR $=1.7$ ) compared to female students, adj.P $=0.046$ and 
adj.P $=0.012$, respectively. Students in their third and above years $(\beta=0.857$, adj.OR $=2.2)$ reported insufficient water intake compared to students in their first and second years, adj.P $=0.003$. Obesity in students was a significantly associated factor with fast food consumption ( $\beta=0.48$, adj.OR $=1.8$ ), nighteating habits $(\beta=0.27$, adj. $\mathrm{OR}=1.3$ ) and skipping meals $(\beta=0.41$, adj.OR $=1.5)$ compared to normal weight students, adj.P $=0.002$, adj. $\mathrm{P}=0.004$ and adj. $\mathrm{P}=0.003$, respectively.

\begin{tabular}{|c|c|c|c|c|c|c|c|c|c|}
\hline & \multicolumn{3}{|c|}{$\begin{array}{l}\text { Gender Females }{ }^{0} \text {; } \\
\text { Males }^{1}\end{array}$} & \multicolumn{3}{|c|}{$\begin{array}{l}\text { Academic year } 1^{\mathrm{ST}} \& 2^{\mathrm{ND} 0} ; 3^{\mathrm{RD}} \& \\
\text { above }^{1}\end{array}$} & \multicolumn{3}{|c|}{$\begin{array}{l}\text { BMI (category) Under/Normal }{ }^{0} \text {;Pre- } \\
\text { obese/obese }^{1}\end{array}$} \\
\hline & $\beta$ & adj.OR & {$[95 \% \mathrm{Cl}]$} & $\beta$ & adj.OR & {$[95 \% \mathrm{Cl}]$} & $\beta$ & adj.OR & {$[95 \% \mathrm{Cl}]$} \\
\hline \multirow[t]{2}{*}{ Sweetened beverages } & 0.119 & 1.1 & $\begin{array}{l}{[0.7-} \\
1.7]\end{array}$ & -0.084 & 0.9 & {$[0.6-1.4]$} & 0.160 & 1.2 & {$[1-1.4]$} \\
\hline & \multicolumn{3}{|c|}{ adj. $P=0.585$} & \multicolumn{3}{|c|}{ adj. $P=0.706$} & \multicolumn{3}{|c|}{ adj.P = 0.120} \\
\hline \multirow[t]{2}{*}{ Insufficient hydration } & $\begin{array}{l}- \\
1.058\end{array}$ & 0.3 & $\begin{array}{l}{[0.2-} \\
0.6]\end{array}$ & 0.857 & 2.2 & [1.3-3.8] & 0.001 & 0.9 & {$[0.7-1.2]$} \\
\hline & \multicolumn{3}{|c|}{ adj.P $<0.001^{*}$} & \multicolumn{3}{|c|}{$\operatorname{adj} . P=0.003^{*}$} & \multicolumn{3}{|c|}{ adj. $P=0.399$} \\
\hline \multirow[t]{2}{*}{ Drinking energy drinks } & 0.162 & 1.2 & $\begin{array}{l}{[0.7-} \\
2.1]\end{array}$ & -0.170 & 0.8 & {$[0.5-1.5]$} & 0.018 & 1.0 & {$[0.7-1.3]$} \\
\hline & \multicolumn{3}{|c|}{ adj.P = 0.572} & \multicolumn{3}{|c|}{ adj. $P=0.555$} & \multicolumn{3}{|c|}{ adj.P $=0.999$} \\
\hline \multirow[t]{2}{*}{ Irregular meal times } & 0.425 & 1.5 & $\begin{array}{l}{[1.0-} \\
2.3]\end{array}$ & -0.118 & 0.6 & [0.6-1.4] & 0.272 & 0.9 & {$[0.8-1.1]$} \\
\hline & \multicolumn{3}{|c|}{ adj.P $=0.046^{\star}$} & \multicolumn{3}{|c|}{ adj. $P=0.588$} & \multicolumn{3}{|c|}{ adj. $P=0.386$} \\
\hline \multirow[t]{2}{*}{$\begin{array}{l}\text { Snacks between } \\
\text { meals }\end{array}$} & $-\overline{-}-$ & 0.7 & $\begin{array}{l}{[0.4-} \\
1.1]\end{array}$ & -0.437 & 0.8 & {$[0.8-1.1]$} & -0.057 & 1.0 & [0.8-1.3] \\
\hline & \multicolumn{3}{|c|}{ adj.P $=0.146$} & \multicolumn{3}{|c|}{ adj. $P=0.109$} & \multicolumn{3}{|c|}{ adj.P $=0.895$} \\
\hline \multirow[t]{2}{*}{ Skipping meals } & $\begin{array}{l}- \\
0.755\end{array}$ & 0.5 & $\begin{array}{l}{[0.3-} \\
0.8]\end{array}$ & -0.271 & 0.7 & {$[0.5-1.2]$} & 0.160 & 1.5 & [1.2-1.9] \\
\hline & \multicolumn{3}{|c|}{ adj. $P=0.001^{*}$} & \multicolumn{3}{|c|}{ adj. $P=0.274$} & \multicolumn{3}{|c|}{ adj.P $=0.003^{*}$} \\
\hline \multirow[t]{2}{*}{ Night eating habit } & 0.208 & 1.2 & $\begin{array}{l}{[0.81-} \\
1.9]\end{array}$ & -0.225 & 0.8 & {$[0.5-1.2]$} & 0.001 & 1.3 & {$[1.1-1.6]$} \\
\hline & \multicolumn{3}{|c|}{ adj. $P=0.330$} & \multicolumn{3}{|c|}{ adj. $P=0.305$} & \multicolumn{3}{|c|}{ adj.P $=0.004^{*}$} \\
\hline \multirow[t]{2}{*}{$\begin{array}{l}\text { Insufficient fruit/ } \\
\text { vegetable }\end{array}$} & 0.256 & 1.3 & $\begin{array}{l}{[0.7-} \\
2.4]\end{array}$ & 0.263 & 0.6 & {$[0.7-2.5]$} & 0.018 & 1.09 & {$[0.8-1.6]$} \\
\hline & \multicolumn{3}{|c|}{ adj.P $=0.420$} & $\operatorname{adj} . P=$ & & & $\operatorname{adj} . P=$ & & \\
\hline Insufficient seafood & 0.553 & 1.7 & $\begin{array}{l}{[1.1-} \\
2.7]\end{array}$ & -0.419 & 0.8 & [0.4-1.0] & 0.272 & 1 & [0.8-1.2] \\
\hline & adj.P $=$ & $=0.012^{\star}$ & & $\operatorname{adj} . P=0$ & & & $\operatorname{adj} . P=$ & & \\
\hline $\begin{array}{l}\text { Fast food } \\
\text { consumption }\end{array}$ & $\begin{array}{l}- \\
0.490\end{array}$ & 0.6 & $\begin{array}{l}{[0.4-} \\
1.1]\end{array}$ & 0.106 & 0.7 & {$[0.6-2]$} & -0.057 & 1.8 & {$[1.2-2.6]$} \\
\hline & adj.P $=$ & $=0.089$ & & $\operatorname{adj} . P=0$ & & & adj.P $=$ & & \\
\hline
\end{tabular}

TABLE 3: Factors associated with unhealthy dietary habits with $95 \%$ confidence interval

*Statistically significant at $P<0.05 ; \mathrm{t}=$ Student's t-test; $0=$ reference group, $1=$ compared group, $\beta=$ coefficient of determination, OR = odds ratio, adj = adjusted, $\mathrm{Cl}=$ confidence interval

\section{Discussion}

Students enrolled in faculties of health sciences are expected to be more cautious about their diet, as their knowledge sought from the academic curricula should reflect primarily on their dietary habits. These 
students are the future physicians, pharmacists, nurses or other allied health care specialists, who are pictured as role models to their patients, families, and community. Readers might debate the nature of the relationship between the quality of dietary habits and academic performance, as an altered diet might not directly affect the academic performance. Numerous mediating or contributing factors might also influence academic performance, such as physical activity, sleep hygiene, and methods of teaching/learning. It is also speculated that poor academic performance might alter the dietary habit, due to stress or depression. The primary message to college students is that adherence to a healthy dietary habit is not a pathway to better academic performance, but rather to promote their personal health and to exemplify themselves as influential role models within their community.

The consumption levels of drinking sweetened beverages have increased three folds in the past two decades, and regular daily consumption has been associated with multiple health problems such as diabetes, tooth decay and heart diseases [14]. The relationship between sugars in soft drinks and health has been examined in the context of metabolic disorders, yet experimental evidence in human and animals suggested that highfructose corn syrup and sucrose found in soft drinks resulted in adverse effects on the hippocampus in the brain that is responsible for learning and memorizing [15].

The academic performance of American students who drink energy beverages at least once weekly has been reported to be lower than those who didn’t [16]. Side effects of energy drinks such as headaches and heart palpitations have been reported widely in literature, and this phenomenon is becoming more prevalent among young adults [17]. Students usually engage in energy drink consumption to compensate for sleep deprivation or to gain energy [18]. Therefore it is important to correct the misconception among college students that by resorting to energy beverages, their academic performance will improve. Lower gastrointestinal digested foods such as well balanced meals (especially breakfasts) provide students with a more sustained energy release during the day, thus creating a better glucose environment for the brain and energy for the body.

Fish carries many health benefits, such as omega-3 long-chain polyunsaturated fatty acids that are not only important for cardiovascular health but to the many aspects of brain functioning such as neuronal membrane fluidity, neurotransmission, signal transduction and blood-brain barrier functions [19]. Two studies have acknowledged the fact that omega- 3 intake had significantly improved academic and cognitive performance $[20,21]$. Therefore, college students ought to consume a diverse diet of proteins, with specific attention to at least $227 \mathrm{~g}$ seafood on a weekly bases [13].

Gender differences were observed with regard to insufficient hydration, irregular meal times, skipping meals, and insufficient seafood. Studies have shown that females tend to consume more fruits/vegetables, legumes, and sweets/cakes in comparison to males [22]. Males tend to consume fish or food richer in fat, such as meat and soft/carbonated drinks [22]. Generally, females tend to invest in matters related to food quality/quantity; therefore, they have a better knowledge of nutrition and weight loss measures [23]. Thus, the eating behaviors of females and males will be different. Females are more likely to eat low-calorie foods and evade overeating by skipping meals, which was similar to findings in this setting [24].

Obesity was associated with skipping meals, night eating habits, and fast food consumption. This logic finding was similar to findings reported in the literature, as a night-eating habit was classified as a dysfunction of the circadian rhythm, a disassociation between eating and sleeping. This unhealthy dietary habit is characterized by a lack of desire to eat breakfast, a strong urge to eat between dinner and sleep or during the night, and linking eating to sleeping [25]. Numerous studies have proven an association between night eating habits and obesity [25]. Inconsistent results were present when exploring gender differences with night eating habits [26]. In addition, the timing of meals is related to obesity, and skipping breakfast significantly influences both waist circumference and BMI [27]. One study concluded that eating breakfast > 4 times per week prevents excessive body weight gain in comparison to skipping breakfast in both genders [28]. Similar types of results were found in our present study; fast food consumption has been reported to be higher among younger adults (mostly men), and it was strongly associated with obesity [29].

Few limitations have been encountered in this study. The nature of the retrospective design entails that there is a slight chance of recall bias in terms of detailed dietary habits. Dietary habits might not be consistent with time, so statements were focused on short time intervals, i.e. daily or weekly, to overcome these recall biases. Other unhealthy dietary habits haven't been questioned in this study, such as consumption of desserts, salt intake, coffee intake, and alcohol consumption. Findings in this study can be generalized to other student populations, as the analyzed sample is representative of a major university that encompasses several faculties of health sciences.

\section{Recommendations}

All students, whether pursuing a health-related or non-health related specialty, are advised to adopt healthy dietary habits and encourage their peers to do so. For college administrators, a set of environmental modifications may influence students and boost their compliance with healthy diets. These include posting flyers/posters, presenting awareness seminars, and campaigns throughout the academic year. Labeling cafeteria meals with brief instructions on the nutritional values/calories would visually remind students of 
what they are buying and consuming. Vending machines within the college premises could provide healthier snacks too. At the governmental levels, firm verdicts are required to elevate taxation on sugar-sweetened beverages and energy drinks, to favor the purchase of better healthy drinks such as fresh juices and shakes.

\section{Conclusions}

This present study revealed that the compliance of college students enrolled in health science faculties with healthy dietary habits was less than optimal. These students are the future role models within their community and should be more vigilant about their dietary lifestyle. Gender differences were observed in regards to insufficient hydration, skipping of meals and insufficient seafood consumption. Obesity in college students was associated with skipping meals, night-eating habits, and fast food consumption.

\section{Additional Information \\ Disclosures}

Human subjects: Consent was obtained by all participants in this study. King Abdullah International Medical Research Center issued approval RC18/146. A self-explanatory letter of invitation to participate was presented to each of the participants. All participants had given informed consents for their participation in the research presented in this manuscript with full knowledge of the possible risks and benefits of participation. Participants consented by ticking “agree”, indicating their agreement to provide their feedback for this research study. The study was approved by the Institutional Review Board of Ministry of National Guard Health Affairs, Riyadh, Saudi Arabia (Protocol \# RC 18/146). Studies conducted followed the recommendations of the International Conference on Harmonization for Good Clinical Practice (ICH-GCP). . Animal subjects: All authors have confirmed that this study did not involve animal subjects or tissue. Conflicts of interest: In compliance with the ICMJE uniform disclosure form, all authors declare the following: Payment/services info: All authors have declared that no financial support was received from any organization for the submitted work. Financial relationships: All authors have declared that they have no financial relationships at present or within the previous three years with any organizations that might have an interest in the submitted work. Other relationships: All authors have declared that there are no other relationships or activities that could appear to have influenced the submitted work.

\section{Acknowledgements}

This study was approved and monitored by King Abdullah International Medical Research Center, King Saud bin Abdulaziz University for Health Sciences, Riyadh, Saudi Arabia. The authors would like to thank the Research Office and the Institutional Review Board for their tremendous support. We would also like to thank King Fahad Medical City and their Research Center.

\section{References}

1. Gibbs HD, Ellerbeck EF, Gajewski B, Zhang C, Sullivan DK: The nutrition literacy assessment instrument is a valid and reliable measure of nutrition literacy in adults with chronic disease. J Nutr Educ Behav. 2018, 50:247-57. 10.1016/j.jneb.2017.10.008

2. Głąbska D, Książek A, Guzek D: Development and validation of the brief folate-specific food frequency questionnaire for young women's diet assessment. Int J Environ Res Public Health. 2017, 14:1574.

3. Azzeh FS, Bukhari HM, Header EA, Ghabashi MA, Al-Mashi SS, Noorwali NM: Trends in overweight or obesity and other anthropometric indices in adults aged 18-60 years in western Saudi Arabia. Ann Saudi Med. 2017, 37:106-13.

4. Malik VS, Popkin BM, Bray GA, Després JP, Willett WC, Hu FB: Sugar-sweetened beverages and risk of metabolic syndrome and type 2 diabetes: a meta-analysis. Diabetes Care. 2010, 33:2477-83. 10.2337/dc101079

5. Gandy J: Water intake: validity of population assessment and recommendations . Eur J Nutr. 2015 , 54:11-6.

6. Rooney C, McKinley MC, Appleton KM, et al.: How much is '5-a-day'? A qualitative investigation into consumer understanding of fruit and vegetable intake guidelines. J Acad Nutr Diet. 2017, 30:105-13. 10.1111/ihn.12393

7. NIH/National Heart, Lung, And Blood Institute. Eating at fast-food restaurants more than twice per week is associated with more weight gain and insulin resistance in otherwise healthy young adults. (2018). Accessed: July 22, 2018: https://www.sciencedaily.com/releases/2005/01/050104105659.htm.

8. Farshchi HR, Taylor MA, Macdonald IA: Regular meal frequency creates more appropriate insulin sensitivity and lipid profiles compared with irregular meal frequency in healthy lean women. Eur J Clin Nutr. 2004, 58:1071. 10.1038/sj.ejcn.1601935

9. Lim CS, Gowey MA, Cohen MJ, Silverstein J, Janicke DM: Unhealthy weight control behaviors mediate the association between weight status and weight-specific health-related quality of life in treatment-seeking youth who are obese. Eat Weight Disord. 2017 , 22:125-32. 10.1007/s40519-016-0262-z

10. Yahia N, Brown C, Potter S, et al.: Night eating syndrome and its association with weight status, physical activity, eating habits, smoking status, and sleep patterns among college students. Eat Weight Disord. 2017, 22:421-33. 10.1007/s40519-017-0403-z

11. De Vet E, Stok FM, De Wit JB, De Ridder DT: The habitual nature of unhealthy snacking: how powerful are habits in adolescence?. Appetite. 2015, 95:182-7. 10.1016/j.appet.2015.07.010

12. Al-Shaar L, Vercammen K, Lu C, Richardson S, Tamez M, Mattei J: Health effects and public health concerns of energy drink consumption in the United States: a mini-review. Front Public Health. 2017, 31:225. 
13. McGuire S: U.S. Department of Agriculture and U.S. Department of Health and Human Services, Dietary Guidelines for Americans, 2010. 7th Edition, Washington, DC: U.S. Government Printing Office, January 2011. Adv Nutr. 2017, 5:225. 10.3389/fpubh.2017.00225

14. Crichton G, Alkerwi A, Elias M: Diet soft drink consumption is associated with the metabolic syndrome: a two sample comparison. Nutrients. 2015, 7:3569-86. 10.3390/nu7053569.

15. Haftoglou S: Relationship Between Sugar Sweetened Beverage Consumption and Academic Performance Among Elementary and Middle School Children (Doctoral dissertation, UCLA). UCLA, 2015.

16. Champlin SE, Pasch KE, Perry CL: Is the consumption of energy drinks associated with academic achievement among college students? J Prim Prev. 2016, 37:345-59.

17. Miller KE: Wired: energy drinks, jock identity, masculine norms, and risk taking . J Am Coll Health. 2008, 56:481-90.

18. Attila S, Çakir B: Energy-drink consumption in college students and associated factors . Nutrition. 2011, 27:316-22. 10.1016/j.nut.2010.02.008

19. Assisi A, Banzi R, Buonocore C, et al.: Fish oil and mental health: the role of $n-3$ long-chain polyunsaturated fatty acids in cognitive development and neurological disorders. Int Clin Psychopharmacol. 2006, 21:319-36. 10.1097/01.yic.0000224790.98534.11

20. Kim JL, Winkvist A, Åberg MA, Åberg N, Sundberg R, Torén K, Brisman J: Fish consumption and school grades in Swedish adolescents: a study of the large general population. Acta Paediatrica. 2010, 99:72-7. 10.1111/j.1651-2227.2009.01545.x

21. Åberg MA, Åberg N, Brisman J, Sundberg R, Winkvist A, Torén K: Fish intake of Swedish male adolescents is a predictor of cognitive performance. Acta paediatrica. 2009 , 98:555-60. 10.1111/j.1651-2227.2008.01103.x

22. Masella R, Malorni W: Gender-related differences in dietary habits. Clinical Management Issues. 2017, 10:11.

23. Manippa V, Padulo C, van der Laan LN, Brancucci A: Gender differences in food choice: effects of superior temporal sulcus stimulation. Front Hum Neurosci. 2017, 7:597. 10.3389/fnhum.2017.00597

24. Chan Sook Wah: Gender differences in eating behaviour. Int J Bus Econ Man. 2016, 4:Accessed: October 28, 2019: http://www.ftms.edu.my/journals/pdf/IJABM/Nov2016/116-121.pdf.

25. Cleator J, Abbott J, Judd P, Sutton C, Wilding JP: Night eating syndrome: implications for severe obesity . Nutr Diabetes. 2012, 2:44. 10.1038/nutd.2012.16

26. Hernandez E, Kim M, Kim WG, Yoon J: Nutritional aspects of night eating and its association with weight status among Korean adolescents. Nutr Res Pract. 2016, 10:448-55. 10.4162/nrp.2016.10.4.448

27. Watanabe Y, Saito I, Henmi I, et al.: Skipping breakfast is correlated with obesity. J Rural Med. 2014, 9:51-8. $10.2185 / \mathrm{jrm} .2887$

28. Sakurai M, Yoshita K, Nakamura K, et al.: Skipping breakfast and 5-year changes in body mass index and waist circumference in Japanese men and women. Obes Sci Pract. 2017, 3:162-70. 10.1002/osp4.106

29. Anderson B, Lyon-Callo S, Fussman C, Imes G, Rafferty AP: Fast-food consumption and obesity among Michigan adults. Prev Chronic Dis. 2011, 8:4. 